pushed into the trachea during intubation. It was then rather difficult to remove the prosthesis without damaging the vocal chords.

Attention was recently drawn to this problem when Coman described three similar cases in Australia. ${ }^{1}$ The most alarming situation was when a patient inhaled his partial denture at the beginning of a parachute jump.

There is an obvious need for greater awareness of the risks of wearing these prostheses. Various measures would minimize the risks to which the case described draws our attention. Firstly, there should be some radio-apaque material included in the prosthesis. Secondly, the incorporation of metal clips to attach the prosthesis to neighbouring teeth reduces the dangers of dislodgement-though such hooks are not without dangers. Coman describes a paraoesophageal abscess resulting from a hook causing the prosthesis to become stuck in the oesophagus for some three weeks. Thirdly, regular checks to ensure that the prosthesis fits well are essential.

It would seem a wise precaution to remove these potentially lethal pieces of apparatus before engaging in violent exercise and probably also at night. Neither of these pieces of advice was given to the patient in question. -I am, etc.,

\section{London N.1}

HARVEY WHITE 1 Coman, W. B., Medical fournal of Australia,

\section{The Cystic Meniscus}

SIR,-The assertation in your leading article (1 September, D. 466) that "removal of the cysts alone results in a high proportion of recurrence" is not my experience in operating on 19 cases of cystic menisci without tear, treated by local excision of the cystic areas. Eighteen cases were followed up, all for more than two years and some dating back to 1961. No recurrence of the cystic condition was found. I agree that complete removal of the cysts and meniscus may sometimes be a difficult procedure. Removal of the cystic area leaving the intact meniscus spares the joint much trauma. The convalescence following preservation of the meniscus is quicker. The meniscus has important functions and should be preserved if possible. Removal of the cystic area relieves symptoms and gives a stable knee joint.

The patient is positioned as for meniscectomy with tourniquet. Incision is made over the centre of the swelling downwards and medially. The capsule is split in line with the skin incision. This is usually slightly more posterior than the capsule incision for lateral meniscectomy-that is, it is not through the weak area which is situated between the patellar tendon and the strong band which forms the medial margin of determination of the iliotibial tract. The capsule is undermined with a scissors. Oedema of the synovia overlying the cystic area is often noted. The outer margins of the cystic area are defined through the split capsule before anything further is done. A small transverse incision is made along the joint line-above the cystic area if possible. This opens the joint and with a three sharp- pronged retractor, the meniscus is pulled towards the operator. If a tear of the meniscus is present, the meniscus is removed together with the cystic area. If the meniscus is intact, the cystic degenerated area is cut cleanly off the meniscus with a knife. The raw area of the intact meniscus is inspected and if any glistening spots are present, they are scraped off with a knife until the remaining meniscus is clear of all little cystic areas. The capsule is closed without difficulty sometimes leaving a gap in the synovia, which does not seem to matter.-I am, etc.,

Orthopaedic Hospital

Croom, Co. Limerick

JOHN P. KeLLY eland

\section{Seat Belts}

SIR,-To date, the seat belt balance sheet in Victoria, Australia, is impressive. On the one side is the compulsory fitting of seat belts in cars manufactured in the year 1969 and subsequently. On the other side is the lowered mortality and dramatically reduced incidence of eye injuries, facial middle third fractures and lacerations, spinal and head injuries, and crushed chests. Injuries caused by seat belts are minor compared with the certain death prevented.

No claim is made that the best designs are used, but it is known that the simple two-point lap belt is effective; the threepoint lap-sash belt more so. And it is known that people will not wear seat belts until it becomes compulsory, as it is in any airliner taking off or coming in to land.

So definite is the evidence in favour of seat belts that the Road Trauma Committee of the Royal Australasian College of Surgeons now seeks extension of the legislation to make it compulsory that all occupants of all motor vehicles be restrained at all times. The design of a suitable harness for small children imposes a problem, but it is one that must be solved because of the merciless way that children are tossed about inside a motor vehicle which brakes sharply, or is involved in a collision.

Professor W. Gissane is correct when he concludes his letter (30 June, p. 772), by saying: "Perhaps, after all, the Australian legislators were right in introducing compulsory belt wear even at this stage of belt design development."-I am, etc.

E. S. R. HugheS Chairman, Road Trauma Committee,
Royal Australasian College of Surgeons Melbourne, Australia

\section{Grades of Hypothyroidism}

SIR,-We have noted the comments of Drs. R. L. Himsworth and Patricia M. Fraser (4 August, p. 295) and would like to take up the points they raise.

They claim that the group of subjects with subclinical hypothyroidism are the key patients in this group. We would not support this view, and would point out that the purpose of our original paper was merely to demonstrate that there is a spectrum of thyroid function between normality and overt thyroid disease. The placing of patients in categories was carried out to allow the data to be examined more easily. Clearly other classifications could be evolved with more or fewer categories, but it is our view that the definitions which we have suggested provide a practical classification for the further study of subjects with thyroid failure. More detailed studies in the future may demonstrate that some other classification is more suitable, which we shall then be very happy to adopt.

Drs. Himsworth and Fraser are quite correot in saying that we do not state the absolute upper limit of serum TSH in the normal population, and we would apologize for the incorrect reference. The upper limit of normal which we use is $4 \mu \mathrm{U} / \mathrm{ml}$. The problem of defining a normal range is a complex one since all published TSH assays contain normal values which are derived from hospital populations, and the use of such data has considerable limitations. ${ }^{1}$ This is particularly true in relation to thyroid disease in view of the high prevalence of undetected autoimmune thyroid disease and goitre in the general population. Wa are currently carrying out a large scale community survey to clarify this and other problems. It is, however, pertinent to raise two points which would suggest that the value we currently use is probably very close to the "true" upper limit of normal.

(a) A preliminary assessment of data from 236 subjects in our community survey reveals that values in excess of $4 \mu \mathrm{U} / \mathrm{ml}$ have been found in only seven subjects (2.9\%) and only two of these values exceeded $5 \mu \mathrm{U} / \mathrm{ml}(5.8$ and $7 \cdot 0)$. The subjects reported in our paper had a mean serum TSH of $11.2 \mu \mathrm{U} / \mathrm{ml}$, and $20 \%$ of these subjects had values greater than $20 \mu \mathrm{U} / \mathrm{ml}$. Clearly there may be some overlap between our groups 3 and 4 and this was implicit in our description of a spectrum of thyroid function. However, nearly all these subjects had $\mathrm{TSH}$ values in excess (and often greatly in excess) of any value which we have observed in a normal subject.

(b) The subjects with subclinical hypothyroidism were selected on the basis of a raised TSH concentration alone, in the absence of symptoms. All but three of these subjects were later found to have circulating thyroid antibodies-emphasizing the presence of thyroid disease.

It is, of course, not possible to state with certainty the mechanism by which an elevated TSH is sustained in the patients with subclinical hypothyroidism. We would generally assume that such subjects were compensating for marginally reduced thyroid function by an elevated TSH. It seems likely to us that this is mediated through the circulating $\mathrm{T} 4$ and $\mathrm{T} 3$ concentrations since it has been demonstrated that very small variations in thyroid hormone concentration (within the normal range for the population) can have a major effect on $\mathrm{TSH}$ secretion. ${ }^{23}$ We would agree that this remains an open question.

Finally, one must take issue with Drs. Himsworth and Fraser's last sentence. The term subclinical hypothyroidism does seem appropriate since the subjects were asymptomatic and had an elevated serum TSH concentration implying suboptimal circulating thyroid hormone concentration at hypothalamic-pituitary level. Clearly it is possible 
to disagree with this term, but it seems the fluid probably resulted from partial stripappropriate to us and its meaning has been ping of the membranes.

clearly defined.-We are, etc., $\begin{aligned} & \text { R. HALL } \text { gest that hydrorrhoea gravidarum is caused } \\ & \text { David EvERED by some irritant between the membranes and }\end{aligned}$ Department of Medicine,

University of Newcastle upon Tyne

1 Masi, A. T., American fournal of Public Health, Snder, P. J., and Utiger, R. D., fourd
Clinical Investigation, 1972, 51, 2077.

Ormsical, Investigation, 197, S1, 2077. $\mathrm{C}$ Clark, F., Bird, T., Appleton, D., and Hall, R., Clinical Endocrinology, in press.

\section{I.U.D. and Hydrorrhoea}

SIR,-Hydrorrhoea gravidarum is a rare syndrome. I should like to report a case in which the contributory factor was an intrauterine contraceptive device, an association which has not previously been reported.

The patient conceived in spite of a Grafenburg ring which had been inserted two years previously. When some eight weeks pregnant she developed vague lower abdominal pain which resolved slowly over the next three weeks, uterine growth being satisfactory. An ultrasound examination at this time demonstrated an intrauterine pregnancy but failed to show the ring.

At a gestation of 22 weeks she developed a profuse watery vaginal discharge. The size of the uterus was compatible with her dates and the cervical os was tightly closed. The fetal heart was clearly audible and regular. From then on a watery fluid drained intermittently and in great quantity. It was alkaline and glucose free, but contained substantial auantities of protein. No fetal cells could be seen. An abdominal $x$-ray showed a normal fetus with a cephalic presentation. The ring was lying below the fetal head and above the internal os. She remained well until 32 weeks and fetal growth was good, but she then developed some pink staining of her discharge which was shown to be blood. A placental scan showed a grade I anterior placenta praevia.

Uterine growth continued and serial oestriol estimations were satisfactory until 35 weeks gestation when she developed some fresh painless vaginal bleeding, despite which the uterus remained lax and the cervix closed. The fetal heart was audible and regular and this was confirmed by a fetal electrocardiograph which showed no evidence of hypoxia. Bleeding continued throughout the day and so caesarean section was done. On incision of the lower segment a blood clot was seen from which protruded the broken Grafenburg ring. This was lying at the lower edge of the placenta, which had partially separated. The membranes were intact. A live female infant weighing $2.31 \mathrm{~kg}$ was delivered. The pelvis was normal apart from some fibrinous adhesions surrounding the right fallopian tube and ovary. Subsequent progress of mother and child was uneventful and there was no undue vaginal discharge.

Moir suggests 1 the hydrorrhuea gravidarum represents a failure of fusion of the decidua vera and the decidua capsularis. One patient is mentioned who had this complaint in three successive term pregnancies. Paalman and Veer $^{2}$ reported a series of 41 cases in which $11(28.6 \%)$ had an associated placenta circumvallata and nine had a history of bleeding in early pregnancy. They felt that
These reports and the present case sug -

asthmatic aerosol preparations are safe when properly used, 9151820 it appears likely that in sensitive individuals, a combination of overuse hypoxia, adrenergic agents and certain aerosol propellants could produce cardiac arrhythmias and ventricular fibrillation. Increases in either hypoxia or concentration of adrenergic agents would probably increase the likelihood of ventricular fibrillation from these preparations.

The associations noted by Stolley ${ }^{14}$ may have been with a preparation which accidentally combined high concentrations of adrenergic agent with the most cardiotoxic of the propellants. Other combinations of aerosol propellant and adrenergic agent could readily account for the spotty distribution of excess deaths noted by Herxheimer. -I am, etc.

Royal Free Hospital,

Liverpool Road

Kerr, J. Munro, Operative Obstetrics, p. 252 8th edn. by J. Chassar Moir and P. Myerscoug

London, Bailliere Tindall and Cassell, 1971. can fournal of Obstetrics and Gynecology, 1953,

\section{Propellant a Factor in Asthma Deaths?}

SIR,-In suggesting causes of the recent epidemic of deaths among asthmatics both your leading article (25 November 1972, p. 443) and Herxheimer ${ }^{1}$ have overlooked the strong possibility that the propellant used in aerosol cans for dispensing medication may have been a contributor. Some of these aerosol propellants have been implicated in sudden deaths due to "aerosol sniffing," 3 and one aerosol product (Pertussin) has been banned in the United States because of associated sudden deaths. Various halogenated hydrocarbons (haloalkanes), isobutane, propane, vinyl chloride, and other agents have been used as propellants in aerosol cans. ${ }^{24}$ Probably not all, but several of them have been used in preparations for inhalation by asthmatics. Some of these agents, notably some of the haloalkanes, have been shown to be associated with cardiac arrhythmia and ventricular fibrillation as well as other effects in animals. ${ }^{4-12}$ In one human experiment, premature atrial and ventricular contractions were noted after haloalkane and isoproterenol inhalation. ${ }^{13}$ In some of these experiments, it was thought that the agent simply sensitized the heart to anoxia or to exogenous adrenergic agents, ${ }^{412}$ but subsequent experiments have shown cardiac effects without either anoxia or exogenous adrenergic agents. ${ }^{6} 71011$ In addition, "aerosol sniffing" deaths have occurred from aerosols containing no adrenergic agents. ${ }^{2}$ Both anoxia and adrenergic agents, however, enhance the cardiotoxicity of the haloalkanes.4911 12 Stolley focused attention on the high concentration of isoprenaline in some of the preparations for asthmatics, and showed that excess asthma deaths ocurred in those countries that had used the "high concentration" preparations.1"

Herxheimer pointed out that isoprenaline is not cardiotoxic, and pointed out some discrepancies in the distribution of excess asthma deaths which Stolley's hypothesis failed to explain. ${ }^{1}$ He went on to attribute the excess deaths to inadequate medical management as others had done. ${ }^{15}$ Unfortunately, this hypothesis is even less adequate than Stolley's in explaining the distribution of excess asthma deaths. It utterly fails to account for the rise in asthma deaths during the time period which accompanied the introduction of the pressurized aerosol asthma preparations in England, ${ }^{14} 15$ and the fall in those deaths after an official warning about use of pressurized medication by asthmatics was issued. ${ }^{17}$

Although several investigators have argued that
VICTOR E. ARCHER

National Institute for Occupational Safety and

U.S. Department of Health, Education and Welfare, Salt Lake City,
Utah, U.S.A.

1 Herxheimer, H., British Medical fournal, 1972,

Bass, M., Fournal of the American Medical Association, 1970, 212, 2075.
Baselt, R. C., and Cravey, R. H., fournal of
Forensic Sciences, 1968, 13, 407. Reinhardt, C. F., Azar, A., Maxfield, M. E.,
Smith, P. E., and Mullin, L. S..,Archives of 1972, 183, 245 .

Taylor, G. J., Harris, W. S., and Bogdonoff. D., fournal of Clinical Investigation, 1971, Taylor, G. J., and Harris, W. S. Fournal of Laboratory and Clinical Medicine, 1970, 76, 857. Taylor, G. J., and Harris, W. S., Fournal of the American Medical Association, 1970, 214, 81.
Clark, D. G., and Tinston, D. J., Annals of Clark, D. G., and Tinston, D. J., Annals of
Allergy, 1972, 30, 536. Flowers, N. C., and Horan, L. G., Fournal of the
American Medical Assosiation, 1972, 219, 33. American Medical Association, 19ar, C. F., Smith,
Mullin, L. S., Azar, Aeinhardt, Re P. E., and Fabryka, E. F., A merican 33, 389 . Hygiene Association fournal, 1972, 33, 389 . Stopps, G. J., fournal of American Medical Ascociation, 1971, 215, 1501.

Brooks, S. M., Mintz, S., and Weiss. E.,

American Review of Respiratory Disease, 1972.
105.640. Stolley, P. D, Ameriran Review of Respiratory
Diseace. 1972, 105, 883. Harris, M. C., Annals of Allergy, 1971

Smith, J. M.. Lancet, 1966, 1. 1042. M., Lancet. 1969, 2, 279 .

Azar. A., Reinhardt, C. F., Maxfield, M. E.. Smith, P. E., and Mullin, L. S.. American Mcrlure. D A. Tnvicology and Applied Pharma rolory. 1972, 22.221.

Silverglade, A., fournal of the American Metical Association, 1971, 215. 118.

\section{Hypergastrinaemia in Rheumatoid Arthritis}

SIR,-While one may excuse Dr. P. J. Rooney and his nine colleagues (30 June, p. 752) for not knowing of early studies suggesting an increased incidence of achlorhydria in rheumatoid arthritis ${ }^{1-3}$ it is more surprising that they fail to note the report of Buchanan et al. ${ }^{4}$ concerning Sjogren's syndrome. These authors demonstrated achlorhydria in four of six patients with this condition. Since $20 \%$ of the patients reported by Dr. Rooney and colleagues have keratoconjunctivitis sicca this nificance of the demonstrated hypergastrinaemia. As theirs was a preliminary report one wonders whether a further paper is already in preparation describing the results of gastrin assays in patients with Sjogren's syndrome? Should this be the case the authors may care to note that among the many prescient "objectives for further Environmental Health, 1971, 22, 265.
ilen, S. M., and Harris, W. S., fournal of Pharmacology and Experimental Therapeutics, is surely of importance in discussing the sig- 